\title{
Application of lean thinking in health care: a role in emergency departments globally
}

\author{
Wyatt W. Decker • Latha G. Stead
}

Received: 29 July 2008 / Accepted: 30 July 2008 /Published online: 28 August 2008

(C) Springer-Verlag London Ltd 2008

Lean management principles were first developed in the 1950 s in the industrial setting of car manufacturing, and the first laboratory was the Toyota manufacturing plant. Further, Womack and Jones are credited in developing the field [1]. Over the past half a century, lean thinking has become more widely embraced, particularly in manufacturing and industrial settings. More recently, it has been recognized that other entities, including the service industries and health care, may be able to benefit substantially from the implementation of lean and other related methodologies, often broadly described as a "systems engineering" approach to health care [2]. Several years ago, the National Health Service of the UK began deploying lean thinking to hospital management, and this issue has a report from Banerjee et al. entitled "The impact of process re-engineering on patient throughput in emergency departments in the United Kingdom" [3].

Lean thinking has been characterized as "[seeking] to provide what the customer wants, quickly, efficiently, and with little waste" [4]. Womack and Jones have identified five key concepts of lean thinking, outlined below [1].

Value Products should be designed for and with customers, should suit the purpose, and be set at the right price.

Value stream Each step in production must produce value for the customer, eliminating all sources of waste. The concept of waste is far-reaching and may include waiting, travel, mistakes, or inappropriate processing.

Flow The system must flow efficiently, ideally without intermediate storage. Among other things, flow depends on materials being delivered, as and when they are needed, to the quality required.

Pull The process must be flexible and geared to individual demands - producing what customers need when they need it.

W. W. Decker $(\bowtie) \cdot$ L. G. Stead

Emergency Medicine, Mayo Clinic College of Medicine,

Rochester, MN, USA

e-mail: decker.wyatt@mayo.edu
Perfection The aim is perfection. Lean thinking creates an environment of constant review, emphasizing suggestions from the "floor" and learning from previous mistakes.

With the application of these principles to the health-care environment and specifically to emergency medicine, some reflection is required [5].

\section{Value}

The concept of value can be looked at from several perspectives. For example, providing the appropriate amount of testing for diagnostic workup, avoiding excessive or costly tests that may not be indicated, but providing value by ultimately identifying the underlying condition or diagnosis.

\section{Value stream}

The concept is that each step in the production must produce value for the customer, or in the parlance of health-care providers, the patient (though customers can include more than the patient themselves). For those who have been patients in their own or other emergency departments, they likely encountered numerous steps that at least on the surface appear redundant or wasteful. Time is among an individual patient's most precious commodities and is something that health-care systems often squander. Placing a high value on our patients' time and focusing on minimizing the time required between each step in an emergency department can reveal substantial results.

\section{Flow}

The system must flow efficiently. Nowhere is this truer than the over-crowded emergency departments we face globally 
today. The focus on flow is a key aspect of lean thinking that can deliver substantial improvements in emergency department care and patient and provider satisfaction.

\section{Pull}

In an emergency department setting, the concept of pull is somewhat novel and relates to an ability of the providers themselves to indicate when they are ready for more patients. To do this requires significant flexibility in staffing patterns and systems to accommodate variability in patient numbers and acuity.

\section{Perfection}

Though we seldom use the term "perfection" in health care, it is what our patients all want. Further, there are different ways to define perfection, perhaps the most pragmatic being that the patient receives outstanding care in a timely fashion that results in the correct diagnosis and therapy.

As Banerjee and colleagues point out in their description of re-engineering patient throughput in emergency departments, this resulted from a mandate by the National Health Service that the overcrowded EDs throughout the UK consistently have their patients seen and dispositioned within $4 \mathrm{~h}$ of arrival. The authors go on to describe the key themes identified for optimizing patient flow, which were derived by identifying four major groups of patients: (1) those with minor injuries or illness that could be treated and discharged quickly, (2) those who required longer assessment and observation, (3) those requiring hospital admissions, and (4) patients requiring emergency surgical procedures. Key themes that cut across groups included streamlining accelerating access to the most appropriate provider, including eliminating triage altogether; having patients initially evaluated, treated, and discharged in one interaction when appropriate; early access to diagnostic test prioritization; maximizing the care provided to appropriate skill levels of individual provider categories; identifying ED overcrowding early; and having policies and procedures in place building whole system multidisciplinary input; and conducting breach (failure) analysis on a daily basis. Banerjee goes on to share the overall performance data of the emergency services collaborative as well as their own hospital's experience where they were ultimately able to obtain $99.1 \%$ compliance with the $4 \mathrm{~h}$ length of stay. Considering the five key concepts for lean thinking, elements of all five can be identified in Banerjee's report. As one might expect, the greatest emphasis is on flow, and most of the initiatives described focused on techniques to eliminate waste and improve patient flow. However, focus on perfection with daily failure analysis is an important element of success of each individual emergency department hospital.

The study shares some innovations and the result of a system engineering approach to patient flow in overcrowded emergency departments. The study is descriptive in nature and does not include health-care outcomes or patient or provider satisfaction data, all of which would be informative and encouraged in additional studies. The concept of identifying specific work-flow streams was particularly helpful and appears to have allowed the emergency departments to improve patient flows for each of the patient's flow streams that they have identified.

Systems engineering with the focus on lean thinking appears to offer substantial rewards to emergency departments, hospitals, and health systems that embrace these methodologies. Important components to recognize are that embarking on the changes is a journey more than a destination. As an example, by continuing to focus on length of stay, the motivated emergency department will be able to push their length of stay well below 4 h. Second, it takes time to introduce these techniques and skills to hospital and emergency department staff and even more time for the cultural change that is necessary for complete implementation. Embracing systems engineering and lean process thinking must be viewed as a long-term strategic initiative, rather than a quick fix or management fad. Thirdly, resources are not important. Both hospitals and emergency departments with significant resources as well as those with few or none benefit from the application of lean processes. One could argue that it is those hospitals with fewer resources that have the most compelling and urgent reasons to implement lean thinking by minimizing waste of both human resources (time) as well as avoiding unnecessary waste of equipment, supplies, and testing. While further research is necessary, it appears that the increasing embrace of lean thinking and related methodologies to the health-care environment is warranted and results in improved patient care metrics, greater efficiency, and ultimately happier and healthier patients.

\section{References}

1. Womack JP, Jones DT (1996) Lean thinking. Simon and Schuster, London

2. Smith J (2001) Redesigning health care: Radical redesign is a way to radically improve. BMJ 322:1257-1258, 26 May

3. Banerjee A (2008) The impact of process re-engineering on patient throughput in emergency departments in the United Kingdom Int J Emerg Med 1 doi:10.1007/s12245-008-0055-x

4. Young T, Brailsford S, Connell C, Davies R, Harper P, Klein J (2004) Using industrial processes to improve patient care. BMJ 328:162-164, 17 Jan

5. King DL, Ben-Tovin DI, Bassham J (2006) Redesigning emergency department patient flows. Application of lean thinking to health care. Emerg Med Australasia 18:391-397 